
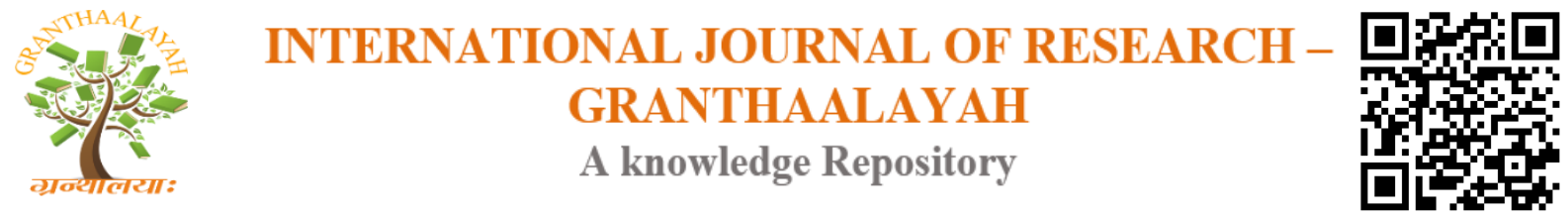

Social

\title{
TECHNOLOGY-ORIENTED SCIENCE INSTRUCTION APPROACHES AND STRATEGIES
}

\author{
Norrie E. Gayeta *1 \\ ${ }^{* 1}$ College of Teacher Education, Batangas State University, Batangas City Philippines
}

\begin{abstract}
Science education has been identified as an effective instrument toward the attainment of goals for global competitiveness. Thus, science teachers need to be conversant with different strategies suited for the best classroom interaction. According to Sorden [1] pedagogy on technology integration creates contexts for authentic learning. New technologies when integrated in a meaningful ways will enhance the production of knowledge and the communication and dissemination of ideas. It is in this context why the researcher intended to determine the approaches and strategies utilized in technology oriented-science instruction. Descriptive research method was used in this study with researcher-made questionnaire as the main data gathering instrument which was complemented by interviews. Respondents were 35 science teachers from Oblates of Saint Joseph schools. Weighted mean was the statistical tools used to treat gathered data.

Results revealed that science teachers often utilized discussion, collaborative, experiential, reflective, metacognitive and expository practices and approaches in technology-oriented science instruction. Results also indicated that the use of simulations and blended learning were moderately utilized in teaching science. Study recommended that science teachers should be provided with more in-service trainings and seminars relative to teaching-learning resources for technology oriented science instruction particularly on the use of simulations, and blended learning, and the resources for these should also be available for teachers use.
\end{abstract}

Keywords: Approaches; Science Instruction; Strategies; Technology Oriented Instruction.

Cite This Article: Norrie E. Gayeta. (2019). "TECHNOLOGY-ORIENTED SCIENCE INSTRUCTION APPROACHES AND STRATEGIES." International Journal of Research - Granthaalayah, 7(5), 202-207. https://doi.org/10.29121/granthaalayah.v7.i5.2019.840.

\section{Introduction}

The world of the $21^{\text {st }}$ century is impacted by rapid changes such as digitization, globalization, trade liberalization, and the environmental revolution. All these changes call for an education that prepares students to meet global challenges. The need for technology-oriented instruction is a must in today's classroom as the new generations of learners are ready to work with the new technologies their familiarity of which can play an important role in the learning process. Technology-aided strategies aimed at providing valuable experiences through instructional 
devices that can be viewed and heard. However, the development and application of new technology-oriented instruction grows as a measure when teachers are trained and have the ability to use and the school is sufficiently equipped with all modern technical means.

One of the visions of science education is to create an environment in which students work together as active learners. To achieve this vision of science education, innovative teaching strategies and approaches are needed much to be carried out by science teachers. To cope with the demands of today's quality science education, the technological evolution and consequent changes in teaching should be part of the teaching-learning processes.

Advances in technology bring forth development and innovation in field of science and delivery of the lessons through their applications. New educational methods using information technology (IT) are being introduced to support complex learning and the development of professional competencies. Davantes [2] posited that teachers should try using technology based instruction in teaching their respective subjects. The use of computer-assisted instruction is an effective tool not only in increasing the academic achievement of the students but also an effective approach in teaching. Along with this, Libid [3] (2006) stated that technology-aided visual aids as instructional materials arouse the interests of learners and make science learning more effective. Drills and exercises allow maximum involvement of the students through computerized instruction and technology-aided instructional materials.

The integration of technology in teaching and learning of science is innovative in nature. Technology has changed the people think, work, and play. Teachers who recognize computers as problem-solving tools change the way they teach. They move from behavioral approach to a more constructivist approach. Students are engaged in their learning using these powerful tools, and can become creators and critics instead of just consumers. According to Lemon [4], it is important that technology has been ever present in classroom and has become more advanced as the technology available evolved. Technology could make teachers and students become more successful. The teacher's responsibility is to discover the judicious use of technology as another tool in the arsenal of teaching that will guide students to exploration, discover, practice, appreciation and wonder at the world they inherit [5]. As the world becomes more complex virtually year to year, most of the last century educational needs have continued to shift from teaching and learning isolated skills and information within each content area to teaching skills that enabled students to solve complex problem across many areas. Moreover, Alcantara [6] added that the teachers should use innovative teaching strategies, instructional materials and educational technology through media, laptop and computer.

Using technology can change the way teachers teach and how much the students learn. This belief stems from the basic philosophy that teachers' do all they call to ensure students are learning. Successful teaching is a result of the systematic use of appropriate strategies for delivering and assessing the learning objectives targeted for each lesson. Every teacher must take into consideration the experiences of their learners as well as the environment they are exposed to.

With this scenario, there is a need to introduce new strategies in teaching science that will transform students into active consumers of learning. This means that teachers should restructure the presentation of materials or devices that will challenge the attention of learners, stimulate their 
ways of thinking and understanding, which make learning more meaningful. In addition, for Sidawi [7] science teachers must modify instruction to teach new skills to students. They should experiment with different methodologies in order to assure that students are provided with appropriate learning alternatives. Furthermore, educators must prepare for a technology-rich future and keep up with change by adopting effective strategies that infuse lessons with appropriate technologies. This makes an authentic assessment needs even more important.

As cited by Brunice [8] technology plays a great role in science teaching. It brings change in teaching and support student centered and inquiry-based learning. The successful use of ICT in science instruction lies on the school's promotion of effective teaching and learning, provision of opportunities for teachers, funding of school-based projects and increasing the access to online resources. Appropriateness of technological devices to age, experience, interest and needs of students must be considered and that media to be used be free from erroneous content. In order to be expert on the use of ICT, teachers should be trained in the use of ICT tools or technology resources to avoid interruptions when using in teaching so that science instruction would enhanced by proper use of these kind of devices.

Sumaong [9] conducted a study on the delivery of science instruction. The findings revealed that science teachers need to include different learning activities such as the use of ICT and the use of other audio-visual materials to motivate the pupils and to build a highly interesting science subject. He recommended that science teachers should attend more in-service trainings and seminars at the division, regional, and national tends to keep themselves abreast with the latest trends and innovations in teaching science.

Relative to this study was the work of Traynor [10] found that utilizing computer-assisted instruction improved instruction over using traditional methods, as sustained by a significant increase in academic achievement. The results of this study showed that using computer-assisted instruction affected cognitive processes and increased motivation in personalizing information, animating objects on the screen and providing practice activities. He concluded that utilization of computer-assisted instruction can incorporate challenges and curiosity, provides a fantasy context and providing learners with choice over their own learning.

Recognizing its importance of technology in teaching, the researcher realizes the need to assess the approaches and strategies utilized by science teachers so as to guide and facilitate students to better learning experience. It is hoped that the results of this study would be of great help to administrators and teachers in planning on how to enhance technology-oriented science instruction. The results of this study may change their views and perspective in integration of innovative learning tool in teaching Science. Likewise, the findings of this study may serve as an eye opener for the teachers to think of alternative educational tools that can help the students become active learners. Moreover, the results of this study may provide information to help them explore more different ways on how to present science lessons in more appealing and interesting ways. As it is, the success in teaching and learning in the classroom depends not only on the teachers' skills but also a great extent on the approaches and strategies they utilized. 


\section{Materials and Methods}

This study used descriptive research method in determining the technology-oriented approaches and strategies utilized in secondary science instruction in Oblates schools during the academic year 2017-2018. The respondents of the study were 35 science teachers from private secondary schools in Oblates of Saint Joseph Schools. The main instrument used in the study was the researcher made - questionnaire which was evaluated, validated, administered, tallied and scored according to the accepted practices in research. Interview was also conducted to science teachers and administrators to substantiate the findings of the study. The data were submitted to the statistician for treatment after which the data are analyzed and interpreted.

\section{Results and Discussions}

The use of different approaches and strategies in teaching help learning process to becomes more interesting for the students. Various techniques provided by the teacher facilitate the attainment of the learning outcome with the end result of a good quality education. Table 1 presents the approaches and strategies utilized in technology oriented science instruction.

Table 1: Approaches and Strategies Utilized in Technology Oriented Science Instruction

\begin{tabular}{|l|l|l|}
\hline Items & WM & VI \\
\hline Discussion & 3.77 & OU \\
\hline Collaborative & 3.66 & OU \\
\hline Experiential Approach & 3.63 & OU \\
\hline Integrated Approach & 3.60 & OU \\
\hline Reflective Approach & 3.57 & OU \\
\hline Metacognitive Approach & 3.54 & OU \\
\hline Direct/Expository Approach & 3.51 & OU \\
\hline Graphic Organizers & 3.49 & MU \\
\hline Demonstration & 3.46 & MU \\
\hline Constructivist Approach & 3.40 & MU \\
\hline Problem Approach & 3.40 & MU \\
\hline Varied Approach & 3.37 & MU \\
\hline Mnemonic & 3.34 & MU \\
\hline Indirect/Guided/Exploratory & 3.31 & MU \\
\hline Simulation & 3.09 & MU \\
\hline Blended Learning & 2.86 & MU \\
\hline Composite Mean & 3.44 & MU \\
\hline
\end{tabular}

Legend: WM=Weighted Mean

OU= Often Utilized

$\mathrm{VI}=$ Verbal Interpretation

MU= Moderately Utilized

From the table often utilized approach in technology oriented science instruction was discussion with weighted mean of 3.77. It seems that OSJ teachers believe that discussion method even traditional in nature enhances the teaching-learning process. It is good to note that even classroom instruction nowadays are surrounded by technology, discussion method still take a great part in student learning. As revealed by the respondents during the interview, discussion is still best employed in some selected science lessons. Discussion skill help students to cope up with the 
required competencies. They added that it is necessary for the teachers to engage students in discussion after every activities provided. This method establishes teachers and students interaction which is important in any learning process.

Collaborative learning was another strategy/approach often utilized in technology oriented science instruction. It obtained a weighted mean of 3.66. This is a clear manifestation that science teachers are aware on the usefulness of collaboration as teaching strategy. Interview conducted revealed that teachers utilized this strategy because it develops students' social skills and the students are more engage in science activities with this approach. This finding support the idea of Slavin[11] that collaborative promotes learning and fosters respect and friendships among diverse groups of students and also to promote peer interaction. This helps the development of language and the learning of concepts and content.

Experiential and integrated approach were another strategies/approaches often utilized in technology oriented science instruction. It obtained a weighted mean of 3.63 and 3.60, respectively. This is a clear manifestation that teachers must provide activities that will offer opportunities for the students for experiential learning. This can be done by the integration of several approaches in teaching. Teachers should allow them to experience the opportunities that will increase their access to online resources and other technology related materials. This finding support the idea of Brunice [8] that technology plays a great role in science teaching because it brings change in teaching and support student centered and inquiry-based learning.

The approach that moderately utilized by science teachers were simulation and blended learning. Apparently, these items got the lowest weighted means of 3.09 to 2.86, respectively. As revealed from the interview this is because their schools have no enough facilities required from the application of these approaches. They added that strong internet connection is also required for the successful implementation of these approaches.

\section{Conclusions and Recommendations}

Utilization of technology oriented approaches and strategies such as discussion, collaborative and experiential approach provide meaningful learning for the learners and enhance science instruction. It is recommended to provide administrative support to science teachers through seminars and trainings relative to technology oriented science instruction particularly on the use of simulations, and blended learning, and the resources for these should also be available for teachers use.

\section{References}

[1] Sorden, S.A., (2014), Cognitive Approach in Instructional Design for Multimedia Learning. USA; Northern Arizona University.

[2] Davantes, R. M. (2006). Beyond E-Learning. John Wiley Sons, Inc.

[3] Libid, L., (2006) "Media and Effect: Comparison of Videotapes and Other Teaching materials in the Classroom Teaching, Modern Teacher.

[4] Lemon, K., (2007). Technology in Classroom. New York; McGraw-Hill Companies, Inc.

[5] Ertmer, P. and Ottenbreit-Leftwich, A. (2010). New Teacher and Student roles in technologysupported classroom, Journal of Research on Technology in Education 
[6] Alcantara, A. (2012). Teaching for innovative learning. Quezon City.

[7] Sidawi, M. M. (2007). Technology: A Catalyst for Teaching and Learning in the Classroom. U.S.: Pearson Education Company.

[8] Brunice, J. (2012). Programming and Media Technique. Manila: National Bookstore.

[9] Sumaong, M. (2012). Validation of the ICT Program in Secondary Science Schools. Philippine Normal University.Unpublished Master's Thesis.

[10] Traynor, R., (2008), "Effects of Computer assisted Instruction on Different Learners", University of California

[11] Slavin, R. E., (2011). Educational Psychology; Theory and Practice. New Jersey. Prentice Hall 